\title{
Respiratory failure in chronic obstructive pulmonary disease
}

\author{
P.M.A. Calverley
}

\begin{abstract}
Respiratory failure in chronic obstructive pulmonary disease. P.M.A. Calverley. (C) ERS Journals Ltd 2003.

ABSTRACT: Respiratory failure is still an important complication of chronic obstructive pulmonary disease (COPD) and hospitalisation with an acute episode being a poor prognostic marker. However, other comorbid conditions, especially cardiovascular disease, are equally powerful predictors of mortality.

The physiological basis of acute respiratory failure in COPD is now clear. Significant ventilation/perfusion mismatching with a relative increase in the physiological dead space leads to hypercapnia and hence acidosis. This is largely the result of a shift to a rapid shallow breathing pattern and a rise in the dead space/tidal volume ratio of each breath. This breathing pattern results from adaptive physiological responses which lessen the risk of respiratory muscle fatigue and minimise breathlessness.

Treatment is directed at reducing the mechanical load applied to each breath, correcting specific precipitating factors, e.g. bacterial infection, and maintaining gas exchange. Both bronchodilators and oral corticosteroids can improve spirometric results in exacerbations of COPD and should be routinely offered to patients with respiratory failure. Controlled oxygen is still not always prescribed appropriately and high inspired oxygen concentrations can lead to severe acidosis by either worsening ventilation/perfusion mismatching and/or inducing a degree of hypoventilation. Ventilatory support using noninvasive ventilation has revolutionised the approach to these patients.

Acute respiratory failure due to chronic obstructive pulmonary disease remains a common medical emergency that can be effectively managed. More attention should be focused on the prevention of these episodes and identifying the factors which cause early relapse.
\end{abstract}

Eur Respir J 2003; 22: Suppl. 47, 26s-30s.

\author{
Correspondence: P.M.A. Calverley \\ Dept of Medicine \\ Clinical Sciences Centre \\ University Hospital Aintree \\ Longmoor Lane \\ Liverpool \\ L9 7AL \\ UK \\ Fax: 441515295888 \\ E-mail: pmacal@liv.ac.uk
}

Keywords: Acidosis

chronic obstructive pulmonary disease

controlled oxygen therapy

respiratory failure

ventilatory control

Received: March 182003

Accepted: April 22003
Respiratory failure is a common and important event, which is frequently associated with severe exacerbations of chronic obstructive pulmonary disease (COPD). The physiological basis of respiratory failure in stable COPD and its management are discussed elsewhere in the present supplement. The principal focus in the current review is the problem of respiratory failure in the COPD patient who becomes acutely ill. This may represent a deterioration in the patient's premorbid condition such that hypoxaemia worsens and hypercapnia develops during a relatively trivial respiratory tract infection, which may be viral or bacterial [1, 2]. Alternatively, these changes may occur for the first time in someone with less severe COPD who encounters a particularly dramatic cause for deterioration, e.g. lobar pneumonia or acute pulmonary oedema. In either case, the physiological abnormality is invariably the development of a significant degree of hypoxaemia $(<8.0 \mathrm{kPa})$ with a variable risk of carbon dioxide retention. When the latter occurs, respiratory acidosis results and this can have grave consequences for the patient, and requires specific management strategies.

\section{Prognostic factors in respiratory failure due to chronic obstructive pulmonary disease}

The presence of hypercapnia during an acute episode of respiratory failure is associated with a significantly higher mortality rate, both initially and during the subsequent 12 months of follow-up [3]. This is specifically related to disease severity, as judged by the need for assisted ventilation, since patients who required ventilation showed a worse 1-yr survival, approximating in one series to only $40 \%$ [4]. This is closely related to their tendency to have an arterial carbon dioxide tension of $>6.7 \mathrm{kPa}(>50 \mathrm{mmHg})$ on admission to the intensive care unit (ICU). Respiratory failure at admission was not the only important prognostic variable. Retrospective review of a range of clinical and physiological measurements strongly suggested that nonrespiratory variables accounted for much of the excess mortality after ICU admission [3]. Such comorbid conditions are a common finding in patients with COPD when multiple pathologies coexist.

Nonetheless, there are good data, collected more recently in the UK, which suggest that the presence of respiratory failure is associated with worse outcome however the patient is managed [5]. Thus $15 \%$ of patients with an arterial blood $\mathrm{pH}$ of $>7.30$ died in one clinical study when managed without assisted ventilation, whereas this rose to $27 \%$ in those with a $\mathrm{pH}$ of $<7.30$ [5]. Although these changes were reduced in the group for whom noninvasive positive pressure ventilation was prescribed, the same relative impact of acidosis was present. Studies looking at other factors related to outcome suggest that, although baseline lung function is a determinant, the patients' overall functional status is a significant predictor of their 1-yr mortality [6], and this is in agreement with recent 
studies which have shown a significant increase in mortality for each point decrement in health status [7].

Many patients who present with respiratory failure are subsequently readmitted, sometimes at quite frequent intervals, and, to date, only one study has investigated the consistency of arterial blood gas tensions at presentation in such patients [8]. In that study, subjects were divided into those who presented with hypoxaemia without hypercapnia (type 1), those who presented with hypoxaemia with hypercapnia but only for the duration of the admission (type 2.1) and those in whom the hypercapnia was persistent (type 2.2). It was found that, although the type 1 admissions were remarkably consistent, individuals who presented with hypercapnia that resolved were just as likely to present on a future occasion with hypercapnia that persisted as an outpatient or without hypercapnia at all. Their prognosis was not significantly different from that of patients who simply showed hypoxaemia, whereas those who were consistently hypoxaemic and hypercapnic on each admission exhibited the worst long-term survival, despite appropriate medical therapy (fig. 1). The fact that, in some patients, hypercapnia resolves during the course of an episode of acute respiratory failure has been recognised since the 1960s [9], but the Irish investigators' study is the only one to date that has provided any information about the prognostic value of this change. It also emphasises the difficulty of making therapeutic decisions, e.g. the introduction of domiciliary oxygen treatment, when patients remain clinically unstable.

\section{Physiological basis of respiratory therapy in chronic obstructive pulmonary disease}

Classical physiological analyses of the changes in blood gas tension during episodes of respiratory failure in COPD have always stressed the role of mismatching of ventilation and perfusion together with relative hypoventilation [10]. More modern techniques using the multiple inert gas elimination technique have confirmed and extended these findings and shown that individuals with a relatively large dead space and a preponderance of ventilation being sent to areas (units) of the lung with a high ratio of ventilation to perfusion are initially hypercapnic [11]. These changes resolve during the

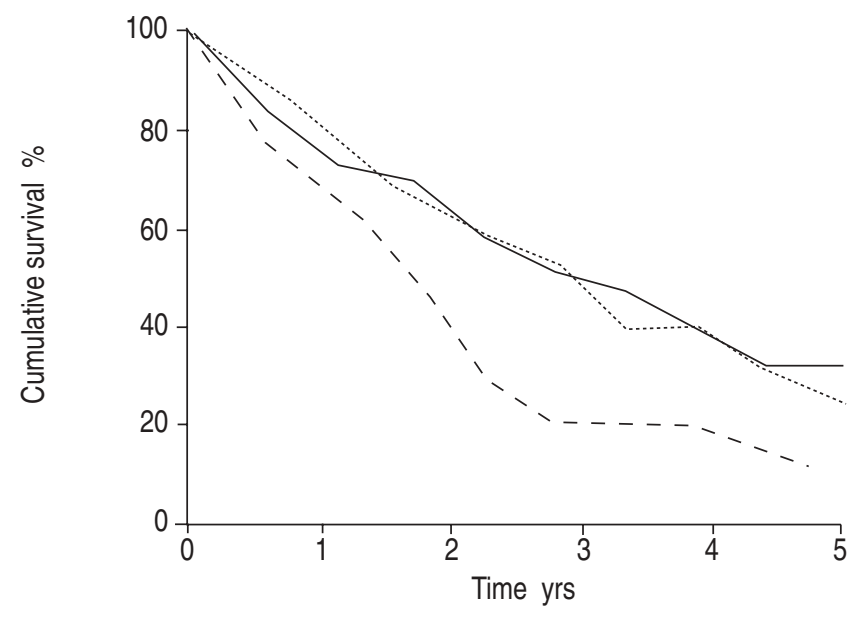

Fig. 1.-Influence of hypercapnia on survival in chronic obstructive pulmonary disease following first admission categorised by consistency of arterial blood gas tensions at presentation ( - : hypoxaemia without hypercapnia (type 1$) ; \cdots \cdots \cdots \cdot$ : hypoxaemia with hypercapnia but only for the duration of the admission (type 2.1 ); - - - - : persistent hypercapnia (type 2.2)). (Reproduced with permission from [8]). course of an exacerbation, and, although the overall ventilation/perfusion distribution is still much broader than that found in healthy subjects, the excess of wasted ventilation falls by the time the patient is discharged with a lower $\mathrm{CO}_{2}$ tension. Hypoxaemia predominantly results from an excess of physiological shunting and distribution of blood to units with lower ventilation/perfusion ratios.

These physiological studies provide an accurate description of blood gas tensions at any specific point but do not indicate how they arise. The initial assumption that significant differences in pulmonary pathology underpin them has proven not to be the case [12], and the relatively dynamic changes in blood gas tensions seen during an episode of acute respiratory failure support this. However, changes in cardiac output as well as an increase in ventilatory demand during an episode of acute respiratory failure can serve to explain the changes in both blood flow and the distribution of ventilation, the former predisposing to hypoxaemia and the latter to hypercapnia.

\section{Mechanisms of hypercapnia in respiratory failure due to chronic obstructive pulmonary disease}

Changes in lung mechanics are thought to be the major determinants of the physiological abnormalities that characterise hypercapnic respiratory failure. In practice, a subject would need to increase their ventilation very substantially to overcome the wasted ventilation in high ventilation/perfusion ratio units, but their inability to do so despite the respiratory stimulus that a rising $\mathrm{CO}_{2}$ tension provides has been the subject of much debate [13]. One useful analysis has been provided by MOXHАM [14], who placed the respiratory muscle pump in the central role, being affected to some extent by the load that it has to overcome, e.g. the expiratory airflow limitation seen in severe COPD, but also by its own capacity to generate pressure, which is significantly reduced by the respiratory muscle shortening that accompanies pulmonary hyperinflation. This is a common and important finding in acute exacerbations of COPD. The drive to the respiratory muscles is itself influenced by chemoreceptor and mechanical receptor inputs and also modulated by sleep. However, sleep structure is probably poor in most episodes of respiratory failure, as in stable disease [15], and sleep-related hypoventilation, therefore, plays a smaller role than would be the case in other chronic respiratory conditions.

There has been much debate about whether respiratory muscle fatigue is the precipitating factor in patients who develop acute respiratory failure. Respiratory muscle fatigue is an important physiological concept, which was initially thought to exist as a chronic state. Fatigue reflects the results of severe loading of the respiratory muscles and their inability to develop the appropriate force or tension to overcome this loading [16]. Characteristically, this process is relieved by rest and much of the benefit of positive pressure ventilation in stable hypercapnic COPD was initially believed to be due to reduction in the degree of chronic fatigue. However, the physiological indices which were believed to reflect the onset of respiratory muscle fatigue have proven to be less robust than initially envisaged. Thus changes in the ratio of the high to low electromyogram power spectrum can be induced by acute respiratory loading and resolve when the load is removed, at least in healthy subjects. Similar problems exist for other indices such as the maximum relaxation rate of the diaphragm, which had been proposed as a specific test to predict the onset of respiratory muscle fatigue. The demonstration in patients with stable COPD that the reduced ability of the diaphragm to develop pressure was a consequence not 
of fatigue but of geometric factors related to chronic hyperinflation [17] led to significant re-evaluation of the role of muscle fatigue in acute respiratory failure. It is now seen more as a "limit condition" than a chronic state. Patients approaching the fatigue threshold usually adopt breathing strategies which reduce the chance of this highly deleterious state occurring.

Initial observations in stable patients showed that their respiratory drive, as assessed by mouth occlusion pressure, was high but that there was a difference in the breathing pattern of patients who showed a high $\mathrm{CO}_{2}$ tension when stable and those that did not [18]. The former tended to exhibit a more rapid shallow breathing pattern and this was investigated subsequently by workers in Italy who found that the tidal volume was inversely related to $\mathrm{CO}_{2}$ tension as was the maximum pleural pressure that the subjects could develop [19]. When the patients were categorised by the intensity of their reported breathlessness using the Medical Research Council dyspnoea scale, those patients using the greatest amount of pleural pressure as a percentage of the maximum were the most breathless and were also the individuals with the shortest inspiratory time and the most rapid breathing pattern (fig. 2).
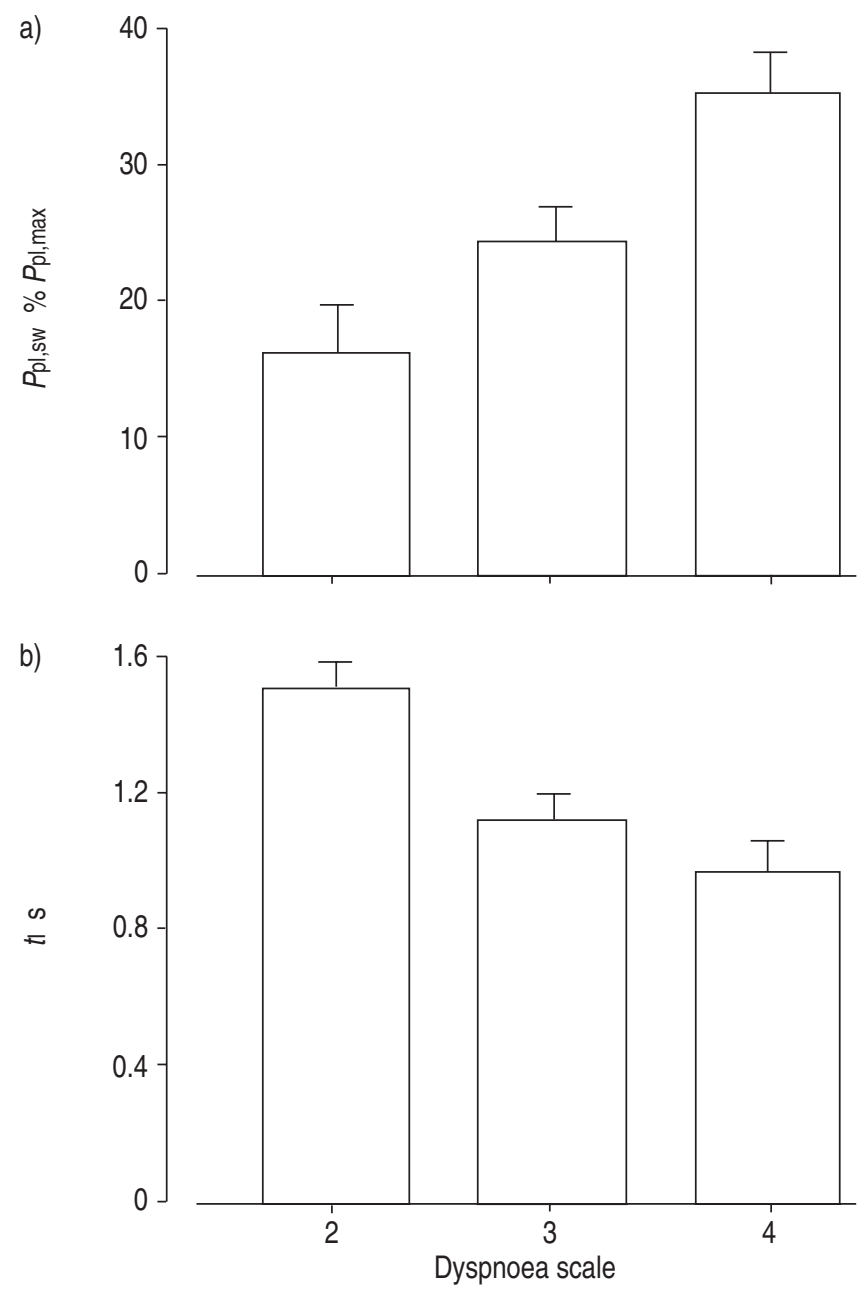

Fig. 2.-Relationship between breathing pattern and Medical Research Council dyspnoea scale in patients with stable chronic obstructive pulmonary disease. Data are presented as mean \pm SD. $P$ pl,sw: swing pleural pressure; $P$ pl,max: maximal pleural pressure; $t \mathrm{r}$ : inspiratory time. (Reproduced with permission from [19]).

\section{Principles of management}

The principles that determine the management of respiratory failure in COPD are very similar to those involved in treating exacerbations of COPD without respiratory failure, although much more attention is paid to the maintenance of appropriate and safe gas exchange.

Clearly, it is important to treat any identified precipitating factors, particularly if they continue to contribute to the abnormal physiological state. Typically, this involves treating lower respiratory tract infections, although, in some patients, management of coexisting pulmonary oedema is equally important. Occasionally people who have inadvertently taken an excess of a sedative drug are still seen. Often, they must be allowed to recover spontaneously, but, when an opiate is involved, the excessive hypoventilation can be reversed by naloxone.

Secondly, it is necessary to reverse the impairment in lung mechanics, which is the commonest precipitating factor for respiratory failure in COPD. This normally involves treatment with bronchodilator drugs and corticosteroids.

Finally, gas exchange itself must be supported. This can often be carried out noninvasively but may require a stay in the ICU. It is always important to review what steps could be taken to prevent or reduce the risk of these episodes after recovery has occurred. There are surprisingly few data about prevention specifically in patients who have experienced an episode of respiratory failure, and, in general, management strategies are inferred from other means known to be effective at preventing exacerbations, e.g. influenza vaccination, reference, or use of long-acting bronchodilators and/or corticosteroids.

\section{Treating precipitants}

There are increasingly good data to indicate that both viral and secondary bacterial infections are the commonest cause of exacerbations of COPD and, by inference, of respiratory failure in this condition. Data specifically looking at respiratory failure have not been presented and this would be a useful area for further study. The commonest viruses involved are rhinovirus and respiratory syncytial virus, whereas the most frequent bacterial pathogens are Haemophilus influenzae and Streptococcus pneumoniae, at least in subjects who are not regularly exposed to antibiotics. Occasionally, patients can develop respiratory failure due to thromboembolism, which can be difficult to detect in advanced disease but is certainly present before death in patients with severe problems who have died due to respiratory failure [12].

There are no good data concerning the role of antiviral therapy in respiratory failure due to COPD and even data regarding antibiotics are sketchy and have normally been inferred from studies in fitter patients. As far as can be determined, antibiotics should be restricted to those patients who show both increased symptoms and purulent sputum [20]. There is a slight beneficial effect from using broadspectrum antibiotics in this setting but data concerning newer compounds are much more limited, a fact which has not prevented their widespread prescription in the ICU.

\section{Reducing the mechanical burden}

Most patients who develop respiratory failure are treated with nebulised bronchodilator drugs, the most common being salbutamol and ipratropium. Data reporting the effects of 
these drugs singly indicate that they are useful whether given to spontaneously breathing or ventilated patients. Whether the combination is helpful is less clear and the few studies that have addressed this suggest that there is not much difference, at least in lung function terms, during the early stages of an exacerbation [21]. In practice, both drugs are commonly recommended in sicker patients [22], being given 4-6 hourly to ensure maximum effective bronchodilation. Older patients may develop troublesome tremor with the $\beta$-agonist, which may require dose reduction or discontinuation.

The data as applied to oral corticosteroids are now fairly clear, with three carefully conducted randomised controlled trials indicating that, in both outpatients and inpatients, the severity of the episode is reduced by treatment with oral corticosteroids compared with placebo [23-25]. Moreover, the rate of lung function improvement is more rapid and the duration of hospitalisation appears to be shorter. One study looking at nebulised corticosteroids over the 3 days of admission found that this was superior to placebo and not significantly different from oral prednisolone. However, the data across all time points indicated that oral therapy was at least as effective, possibly more so [26].

\section{Maintaining gas exchange}

It is seldom difficult to adequately oxygenate patients with acute respiratory failure due to COPD, the major risk being to precipitate $\mathrm{CO}_{2}$ retention and significant acidosis. This is only a significant risk when the inspired oxygen concentration exceeds $\sim 30 \% \quad(30 \mathrm{kPa})$. The mechanism underlying this process has been hotly debated since the 1960s [27], with evidence supporting ventilation/perfusion mismatching in very severe cases [28], whereas $\mathrm{CO}_{2}$ retention in less severe episodes involves an element of hypoventilation secondary to a reduction in hypoxic drive to breathing [29]. Controlled oxygen can be safely administered via a Venturi-based face mask or through nasal prongs. The inspired oxygen concentration is less precisely controlled when prongs are used [30], but the patient is less likely to remove prongs than a face mask [31]. Either way, nursing care is needed to ensure that treatment is used appropriately and blood gas levels should be monitored after treatment to ensure satisfactory therapy without risk of $\mathrm{CO}_{2}$ retention. Ignoring these simple principles has led to many patients being rendered needlessly acidotic, at least as seen in a large survey of practise in a UK metropolitan area [32].

The further management of acidosis usually involves ICU care, although some patients are given respiratory stimulant drugs such as intravenous doxapram to stimulate their already enhanced respiratory drive further. This drug is a potent stimulus to breathing in healthy individuals [33] but appears inferior to noninvasive positive pressure ventilation in COPD patients [34].

The important role of noninvasive ventilation in managing episodes of respiratory failure is fully discussed elsewhere in the present supplement [35]. It has certainly improved care for many chronic obstructive pulmonary disease patients and allowed some to undergo therapy that might otherwise be denied them.

\section{References}

1. Seemungal T, Harper-Owen R, Bhowmik A, et al. Respiratory viruses, symptoms, and inflammatory markers in acute exacerbations and stable chronic obstructive pulmonary disease. Am J Respir Crit Care Med 2001; 164: 1618-1623.

2. Sethi S, Evans N, Grant BJB, Murphy TF. New strains of bacteria and exacerbations of chronic obstructive pulmonary disease. $N$ Engl J Med 2002; 347: 465-471.

3. Seneff MG, Wagner DP, Wagner RP, Zimmerman JE, Knaus WA. Hospital and 1-year survival of patients admitted to intensive care units with acute exacerbation of chronic obstructive pulmonary disease. JAMA 1995; 274: 1852-1857.

4. Connors AFJ, Dawson NV, Thomas C, et al. Outcomes following acute exacerbation of severe chronic obstructive lung disease. The SUPPORT investigators. Am J Respir Crit Care Med 1996; 154: 959-967. (Erratum in Am J Respir Crit Care Med 1997;155: 386).

5. Plant PK, Owen JL, Elliott MW. Early use of non-invasive ventilation for acute exacerbations of chronic obstructive pulmonary disease on general respiratory wards: a multicentre randomised controlled trial. Lancet 2000; 355: 19311935.

6. Menzies R, Gibbons W, Goldberg P. Determinants of weaning and survival among patients with COPD who require mechanical ventilation for acute respiratory failure. Chest 1989; 95: 398-405.

7. Domingo-Salvany A, Lamarca R, Ferrer M, et al. Healthrelated quality of life and mortality in male patients with chronic obstructive pulmonary disease. Am J Respir Crit Care Med 2002; 166: 680-685.

8. Costello R, Deegan P, Fitzpatrick M, McNicholas WT. Reversible hypercapnia in chronic obstructive pulmonary disease: a distinct pattern of respiratory failure with a favorable prognosis. Am J Med 1997; 102: 239-244.

9. Jeffrey AA, Warren PM, Flenley DC. Acute hypercapnic respiratory failure in patients with chronic obstructive lung disease: risk factors and use of guidelines for management. Thorax 1992; 47: 34-40.

10. Rodriguez-Roisin R. Pulmonary gas exchange. In: Gibson GJ, Geddes DM, Costabel U, Sterk PJ, Corrin B, eds. Respiratory Medicine. London, Elsevier Science, 2003; pp. $130-146$.

11. West JB, Wagner PD. Pulmonary gas exchange. Am J Respir Crit Care Med 1998; 157: Suppl. 4, S82-S87.

12. Calverley PM, Howatson R, Flenley DC, Lamb D. Clinicopathological correlations in cor pulmonale. Thorax 1992; 47: 494498.

13. Roussos C, Koutsoukou A. Respiratory failure. Eur Respir J 2003; 22: Suppl. 47, 3s-14s.

14. Moxham J. Respiratory failure: definitions and causes. In: Wetherall DA, Ledingham JM, Warrell D, eds. Oxford Textbook of Medicine. Oxford, Oxford University Press, 1996; pp. 2901-2906.

15. Calverley PM, Brezinova V, Douglas NJ, Catterall JR, Flenley DC. The effect of oxygenation on sleep quality in chronic bronchitis and emphysema. Am Rev Respir Dis 1982; 126: 206-210.

16. Roussos C, Bellemare F, Moxham J. Respiratory muscle fatigue. In: Roussos C, ed. The Thorax. New York, NY, Marcel Dekker, 1995; pp. 1405-1462.

17. Similowski T, Yan S, Gauthier AP, Macklem PT, Bellemare FM. Contractile properties of the human diaphragm during chronic hyperinflation. New Engl J Med 1991; 325: 917-923.

18. Scano G, Spinelli A, Duranti R, et al. Carbon dioxide responsiveness in COPD patients with and without chronic hypercapnia. Eur Respir J 1995; 8: 78-85.

19. Gorini M, Misuri G, Corrado A, et al. Breathing pattern and carbon dioxide retention in severe chronic obstructive pulmonary disease. Thorax 1996; 51: 677-683.

20. Anthonisen NR, Manfreda J, Warren CP, Hershfield ES, Harding GK, Nelson NA. Antibiotic therapy in exacerbations of chronic obstructive pulmonary disease. Ann Intern Med 1987; 106: 196-204.

21. Moayyedi P, Congleton J, Page RL, Pearson SB, Muers MF. Comparison of nebulised salbutamol and ipratropium bromide with salbutamol alone in the treatment of chronic obstructive pulmonary disease. Thorax 1995; 50: 834-837. 
22. Anon. BTS guidelines for the management of chronic obstructive pulmonary disease. Thorax 1997; 52: Suppl. 5, S1-S28.

23. Thompson WH, Nielson $\mathrm{CP}$, Carvalho $\mathrm{P}$, Charan NB, Crowley JJ. Controlled trial of oral prednisone in outpatients with acute COPD exacerbation. Am J Respir Crit Care Med 1996; 154: 407-412.

24. Niewoehner DE, Erbland ML, Deupree RH, et al. Effect of systemic glucocorticoids on exacerbations of chronic obstructive pulmonary disease. New Engl J Med 1999; 340: 1941-1947.

25. Davies L, Angus RM, Calverley PMA. Oral corticosteroids in patients admitted to hospital with exacerbations of chronic obstructive pulmonary disease: a prospective randomised controlled trial. Lancet 1999; 354: 456-460.

26. Maltais F, Ostinelli $\mathrm{J}$, Bourbeau $\mathrm{J}$, et al. Comparison of nebulized budesonide and oral prednisolone with placebo in the treatment of acute exacerbations of chronic obstructive pulmonary disease: a randomized controlled trial. $\mathrm{Am}$ J Respir Crit Care Med 2002; 165: 698-703.

27. Calverley PMA. Oxygen-induced hypercapnia revisited. Lancet 2000; 356: 1538-1539.

28. Aubier M, Murciano D, Milic-Emili J, et al. Effects of the administration of $\mathrm{O}_{2}$ on ventilation and blood gases in patients with chronic obstructive pulmonary disease during acute respiratory failure. Am Rev Respir Dis 1980; 122: 747754.
29. Robinson TD, Freiberg DB, Regnis JA, Young IH. The role of hypoventilation and ventilation-perfusion redistribution in oxygen-induced hypercapnia during acute exacerbations of chronic obstructive pulmonary disease. Am J Respir Crit Care Med 2000; 161: 1524-1529.

30. Bazuaye EA, Stone TN, Corris PA, Gibson GJ. Variability of inspired oxygen concentration with nasal cannulas. Thorax 1992; 47: 609-611.

31. Costello RW, Liston R, McNicholas WT. Compliance at night with low flow oxygen therapy: a comparison of nasal cannulae and Venturi face masks. Thorax 1995; 50: 405-406.

32. Plant PK, Owen JL, Elliott MW. One year period prevalence study of respiratory acidosis in acute exacerbations of COPD: implications for the provision of non-invasive ventilation and oxygen administration. Thorax 2000; 55: 550-554.

33. Calverley PM, Robson RH, Wraith PK, Prescott LF, Flenley DC. The ventilatory effects of doxapram in normal man. Clin Sci 1983; 65: 65-69.

34. Angus RM, Ahmed AA, Fenwick LJ, Peacock AJ. Comparison of the acute effects on gas exchange of nasal ventilation and doxapram in exacerbations of chronic obstructive pulmonary disease. Thorax 1996; 51: 1048-1050.

35. Brochard L. Mechanical ventilation: invasive versus noninvasive. Eur Respir J 2003; 22: Suppl. 47, 31s-37s. 